\title{
El nuevo gobierno de izquierda y el cambio del modelo de comunicación en México
}

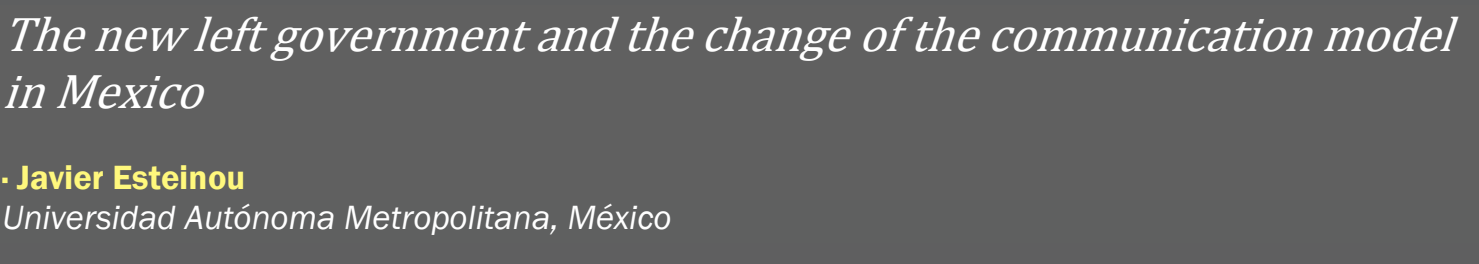

DOI: http://dx.doi.org/10.15304/ricd.3.10.6172

\section{NOTAS BIOGRÁFICAS}

Javier Esteinou es profesor-investigador titular del Departamento de Educación y Comunicación de la Universidad Autónoma Metropolitana, Unidad Xochimilco, México D.F.

Contacto: jesteinou@gmail.com

\section{Resumen}

Con el fin de alcanzar los objetivos planteados en el proyecto de la Cuarta Transformación Histórica el gobierno de Andrés Manuel López Obrador y del frente político de Morena expusieron la necesidad de crear otro modelo de comunicación social que se convierta en un parteaguas que sepulte el tradicional prototipo de difusión de control político. Dicho prototipo comunicativo permitirá informar de forma directa, constante y ágil a la población sobre las políticas públicas adoptadas por el novel gobierno para cumplir con el derecho a la información y crear una opinión pública favorable que le sirva de respaldo subjetivo para gobernar eficazmente.

En este sentido, el nuevo modelo de comunicación de la Cuarta Transformación está compuesto por dos grandes niveles de acción comunicativa que abarcan: por un lado, una fase indirecta de comunicación; y por otro lado, una fase directa de comunicación que en conjunto se convierten en la fuerza político-cultural que cotidianamente le imprimen la dirección colectiva de naturaleza cognitivo-psíquico-ideológico-emocional a la nación.

Sin embargo, la definición de los relevantes lineamientos constitutivos del proyecto de comunicación, es fundamental destacar que ante los grandes desafíos de desarrollo estructural que se deben resolver en México con el fin de edificar otra nación en el siglo XXI, es indispensable que la sociedad reconstruya los procesos democráticos de comunicación para que el proceso de cambio de la nación se realice de manera equilibrada y no sesgada o viciada. Dentro de este escenario, las escuelas de comunicación del país tienen una responsabilidad e importancia central para analizar si lo que se realiza a través de la ejecución del nuevo paradigma de comunicación de la Cuarta Transformación es para crear democracia, pluralidad y libertad de expresión o es para construir centralismo, autoritarismo y Presidencia Imperial.

\section{Abstract}

In order to achieve the objectives set forth in the Fourth Historical Transformation project, the government of Andrés Manuel López Obrador and Morena's political front exposed the need to create another model of social communication that would become a partacho that buried him traditional prototype of diffusion of political control. This communicative prototype will allow the population to inform in a direct, constant and agile manner about the public policies adopted by the 
new government to comply with the right to information and create a favorable public opinion that will serve as subjective support for effective governance.

In this sense, the new communication model of the Fourth Transformation is composed of two great levels of communicative action that encompass: on the one hand, an indirect phase of communication; And on the other hand, a direct phase of communication that together becomes the political-cultural force that is daily printed by the collective direction of a cognitive-psychologicalideological-emotional nature to the nation.

However, the definition of the relevant guidelines of the communication project, it is essential to emphasize that, in view of the great structural development challenges that must be resolved in Mexico in order to build another nation in the twenty-first century, it is indispensable that society reconstructs the democratic processes of communication so that the process of change of the nation is carried out in a balanced and non-biased or vitiated way. Within this scenario, the communication schools of the country have a central responsibility and importance to analyze if what is done through the execution of the new paradigm of communication of the Fourth Transformation is to create democracy, plurality and freedom of expression or is to build centralism, authoritarianism and Imperial Presidency.

\section{Palabras clave}

Transición política, Andrés Manuel López Obrador (AMLO), Cuarta Transformación Histórica en México(4T), modelo de comunicación, democracia comunicativa, autoritarismo informativo, ciudadanización de la comunicación, escuelas de comunicación.

\section{Keywords}

Political transition, Andrés Manuel López Obrador (AMLO), Fourth Historical Transformation in Mexico (4T), communication model, communicative democracy, informational authoritarianism, communication citizenship, communication schools.

\section{Sumario}

1. El tsunami electoral del 2018

2. Los procesos de comunicación y la construcción del nuevo proyecto de nación

3. El modelo de comunicación de la Cuarta Transformación Histórica de México

1.1. Comunicación indirecta vía las tecnologías de información

1.1.1. El emisor

1.1.2. Los mensajes o contenidos

1.1.3. Las audiencias o públicos

1.1.4. La bidireccionalidad o retralimentación

1.2. Comunicación directa con la población

4. Los desafíos democráticos del prototipo de comunicación de la Cuarta Transformación

\section{Contents}

1. The 2018 electoral tsunami

2. Communication processes and the construction of the new nation project

3. The communication model of the Fourth Historical Transformation of Mexico 
1.1. Indirect communication via information technologies

1.1.1. The sender

1.1.2. The messages or contents

1.1.3. Audiences

1.1.4. Bidirectionality or re-feeding

1.2. Direct communication with the population

4. The democratic challenges of the communication prototype of the Fourth Transformation 


\section{EL TSUNAMI ELECTORAL DEL 2018}

Dentro del contexto de agotamiento del modelo de desarrollo neoliberal de México se realizaron las elecciones federales, estatales y locales del $1^{\circ}$ de julio de 2018 para elegir 3 mil 400 cargos públicos de representación popular, dentro de los cuales destacaron la presidencia de la República, 8 gubernaturas, 1 jefe de gobierno, 500 diputados federales, 128 senadores, y 1,596 alcaldes en los municipios de 24 estados en la República Mexicana y 16 alcaldías en la Ciudad de México (Elecciones 2018 serán las más grandes en toda la historia, 2017). El resultado de dicho proceso electoral fue la generación de un enorme tsunami político como nunca antes se había presentado en la historia contemporánea de México, desde la etapa del cardenismo en el siglo XX.

El triunfo arrollador de Andrés Manuel López Obrador (AMLO) y del frente político de Morena (Movimiento de Regeneración Nacional), fue un acontecimiento asombroso sin precedentes en la historia nacional que dejó atónita a la opinión pública mexicana e internacional por la contundencia de los resultados. Esto debido a que la mayoría de la población decidió democráticamente que el país debía encaminarse, por primera vez, en su historia moderna hacia el establecimiento de un gobierno nacionalista de orientación de izquierda.

Así, después de 77 años de las administraciones emanadas del Partido Revolucionario Institucional (PRI) y los 12 años de alternancia política del Partido Acción Nacional (PAN), que provocaron durante muchas décadas la acumulación del enojo, la frustración, el coraje y la desilusión en contra de la clase política dominante, especialmente hacia el PRI y el modelo de desarrollo neoliberal, pues marginaron del crecimiento a enormes mayorías de los beneficios del crecimiento; un sector mayoritario de ciudadanos ejerció un voto de castigo anti sistémico de profundo cambio histórico de la nación hacia un paradigma de izquierda política.

(Mussali, 2018).

En este sentido, se gestó una revolución pacífica que cimbró las bases del viejo sistema político mexicano, generando una transformación del régimen político, donde la coalición "Juntos Haremos Historia" conformado por el frente de Morena, el Partido del Trabajo (PT) y el partido Encuentro Social, encabezado por Andrés Manuel López Obrador; logró la mayor votación a su favor desde que existen comicios presidenciales con competencia pluripartidista en México (Salinas, 2018) De esta forma, se construyó una nueva hegemonía que transformó el status quo político con grandes márgenes de legitimidad, donde el frente de Morena "La Esperanza de México" obtuvo el Poder Ejecutivo con $53.19 \%$ del total de votos; la mayoría del Poder Legislativo con 69 senadores y 306 diputados; las gubernaturas de los estados de Morelos, Chiapas, Tabasco y Veracruz; la jefatura de la Ciudad de México, junto con catorce alcaldías metropolitanas; la mayoría absoluta en ocho de los veinte y seis estados como Sonora, Hidalgo, Tlaxcala, Tabasco, Chiapas, Oaxaca, Estado de México y Colima; finalmente, el 79\% de las voluntades electorales en el país, es decir, conquistó más de 30 millones de votos en todo el territorio nacional ${ }^{1}$.

Mediante este giro político triunfó la joven democracia mexicana creando una ruptura histórica radical que puso fin a un régimen partidocrático que duró más de ocho décadas y media en el país; y gestó una profunda transformación en el mapa del poder político de la República al crear un cambio del régimen hacia la izquierda que dio origen a una nueva etapa político-social que aspira a construir la "Cuarta Transformación de la República" en la historia moderna de México.

\section{LOS PROCESOS DE COMUNICACIÓN Y LA CONSTRUCCIÓN DEL NUEVO PROYECTO DE NACIÓN}

Dentro del contexto de victoria política del 2018, AMLO y el frente partidista de Morena plantearon que para gobernar durante el periodo 2018-2024, era necesario crear una nueva racionalidad de crecimiento concretizada en un nuevo Proyecto de Nación que conllevara un cambio profundo en las principales áreas de funcionamiento, gobernabilidad y desarrollo para consolidar la Cuarta Transformación de la historia contemporánea de México. Así, dicha alianza política formuló que para construir la Cuarta Transformación se deberán seguir, entre otros, los siguientes ejes estructurales del nuevo modelo de desarrollo:

A nivel político separar el poder económico del poder político (López Obrador, 2018); combatir la corrupción en todos los niveles; desmantelar la estructura neoliberal del Estado y de la sociedad; erradicar la impunidad; suprimir los privilegios exorbitados de la clase política; etc. En la esfera económica, rescatar al Estado de la 
red de intereses de los grandes grupos; aplicar un programa de gobierno con severa austeridad republicana; retomar el modelo económico del "desarrollo estabilizador" que operó en otras etapas de México; distribuir la riqueza hacia los sectores más desfavorecidos; recuperar el rol del Estado como actor económico evitando que el mercado asuma el centro gravitacional de la vida pública, económica y política; liberar al campo de su ancestral marginación; etc. (López Veneroni, 2019). En el plano de la democracia, evolucionar de la "democracia representativa" a la "democracia participativa"; someter al Presidente de la República al principio de la revocación del mandato; aplicar las consultas ciudadanas como método de realización de la "democracia directa”, etc. En el terreno de la seguridad, crear una nueva Guardia Nacional de carácter militar para combatir al crimen organizado, etc. En el plano social, garantizar el derecho a la educación y al trabajo, etc. En el rubro de la política exterior, mantener los principios constitucionales de no intervención, autodeterminación de los pueblos, solución pacífica de las controversias, y cooperación para el desarrollo (López Obrador, 2018), etc. En la dimensión ética, crear una Constitución Moral; formar una nueva "ética pública" como base del nuevo Proyecto de Nación, etc. (López Obrador, 2016).

Además de las políticas estructurales anteriores, en el ámbito de la cultura y de la comunicación, se propusieron diversos fundamentos básicos de naturaleza axiológica cultural que constituirán parte esencial de la racionalidad del corazón del nuevo "Proyecto de Nación", dentro de los cuales destacan, los siguientes 15 diagnósticos y directrices:

1.- La decadencia que padecemos en el país se ha producido, tanto por la falta de oportunidades de empleo, estudio y otros satisfactores básicos, como por la pérdida de valores culturales, morales y espirituales (López Obrador, 2018).

2.- Frente a la degradación de la sociedad, la corrupción, el desmantelamiento de las instituciones, la destrucción de la naturaleza, el consumismo, el individualismo posesivo, la concentración de la riqueza y la deshumanización del poder, México necesita un profundo cambio político, económico, social y cultural, que pasa por un cambio moral y ético (Morena, 2018).

3.- Una sociedad como la nuestra hundida en la tristeza y sometida al temor constante de la violencia y la inseguridad, debe realizar un inmenso esfuerzo para recuperar los valores y principios que dieron sentido a la formación de nuestra Nación y que se hallan plasmados en las obras que constituyen nuestro patrimonio histórico y cultural, así como en el potencial creador de miles de hombres y mujeres dedicados al arte y la cultura en nuestras comunidades, pueblos y ciudades (López Obrador, 2016).

4.- La construcción de un nuevo modelo de nación requiere una nueva ética del servicio público que privilegie la atención digna, humana, eficiente y técnicamente competente, así como la participación efectiva de todos los involucrados en el sistema de salud, a través del diálogo sustentado en información (Morena, 2018b).

5.- Para lograr el renacimiento de México es imperioso gestar la revolución de las conciencias hacia una nueva corriente de pensamiento, crítico, solidario, sustentado en la cultura de nuestro pueblo, en su vocación de trabajo y en su generosidad (Morena, 2018). Dicha revolución de las conciencias debe tener en cuenta los siguientes las siguientes dos realidades:

- Una moral basada en la solidaridad, el apoyo mutuo, el respeto a la diversidad religiosa, étnica, cultural, sexual, que promueva el respeto a los derechos humanos, reconozca el sentido de comunidad, el amor al prójimo y el cuidado del medio ambiente.

- No aceptar el predominio del dinero, la mentira y la corrupción, sobre la dignidad, la moral y el bien común (Morena, 2018).

6.- Es necesario hacer realidad el progreso con justicia y, al mismo tiempo, auspiciar una manera de vivir sustentada en el amor a la familia, al prójimo, a la naturaleza, a la patria y a la humanidad (López Obrador, 2016).

7.- Para superar la crisis que enmarca a la sociedad se requiere renovar la moral basada en la solidaridad, el apoyo mutuo, el respeto a la diversidad religiosa, étnica, cultural, sexual, que promueva el respeto a los derechos humanos, reconozca el sentido de comunidad, el amor al prójimo y el cuidado del medio ambiente. No debe aceptarse el predominio del dinero, la mentira y la corrupción, sobre la dignidad, la moral y el bien común (Morena, 2018).

8.- La honestidad puede ser la tabla de salvación de México. Es imprescindible convertir esta virtud en inspiración y forma de vida de las instituciones. La honestidad es un tesoro, la riqueza enterrada. Extraerla del México profundo y reva- 
Iorarla permitirá disponer de recursos económicos para el desarrollo y combatir la infelicidad que por décadas ha sido impuesta al pueblo mediante las "medidas amargas pero necesarias", que han sido aplicadas con el verdadero propósito de favorecer a unos cuantos (Morena, 2018b).

9.- La honestidad es una virtud que forma parte del patrimonio moral del pueblo mexicano. En los pueblos del México profundo se conserva aún la herencia de la civilización mesoamericana, la vida comunitaria y existe una importante reserva de principios para regenerar la vida pública desde abajo. Simplemente se requiere de voluntad política para aprovechar las bondades de esta virtud, exaltarla entre todos para hacerla voluntad colectiva y, en consecuencia, sea sinónimo de buen gobierno (Morena, 2018b).

10.- Es fundamental recuperar la ética política, pues la política es asunto de todos, no sólo de políticos profesionales. Es un derecho participar en los asuntos públicos y sociales. La política se ha pervertido con la corrupción, la compra del voto, el lavado de dinero, el clientelismo y el paternalismo. Debemos luchar por y a través de una ética política que pretenda alcanzar la paz sustentada en el bien común y en el respeto, como la esencia del cambio democrático. La felicidad no la provee la acumulación de bienes materiales sino la procuración del bienestar de tod@s (Morena, 2018).

11.- Se convocará a la sociedad en su conjunto a fortalecer los hábitos de la honestidad y velar por el bien común, pues hacer realidad estos ideales depende, en mucho, de involucrar a todas las mexicanas y a todos los mexicanos (Morena, 2018b).

12.- Abolir la corrupción significará toda una revolución social pacífica, la austeridad republicana se convertirá en ejemplo de rectitud, moralidad y en la principal fuente para financiar el desarrollo (AMLO y doce de sus polémicas propuestas para el 2018, 21 de noviembre de 2016).

13.- Durante el periodo neoliberal se "gestó una generación de valores que ocasionó un proceso de degradación progresivo. Una decadencia, que cada día va a estar peor.

Hay que detener este proceso con los valores que hay, que afortunadamente existen en nuestra población, valores culturales, morales, espirituales, la honestidad de nuestro pueblo, regenerar la vida pública, iniciar una etapa nueva, acompañada de acciones, como los programas sociales, el buen ejemplo.

Para ello, se distribuirá la "Cartilla Moral" que escribió Alfonso Reyes. A ocho millones de adultos mayores que están recibiendo pensión se les enviará "Cartilla" para que nos ayuden con sus hijos, con sus nietos, de manera voluntaria, para fortalecer valores, para que no domine lo material, para que no sea el dinero, lo material, lo que determine nuestras vidas.

Es un proceso, pero se logrará la regeneración de la vida pública. (López Obrador, 2019).

14.- Se preservará nuestra memoria histórica. Se promoverá la lectura en general y particularmente de la historia, el civismo, la ética; nunca se olvidará de dónde venimos; por eso se exaltarán nuestras culturas originarias, las transformaciones históricas y el sacrificio de nuestros héroes (López Obrador, 2018).

15.- Finalmente, con la realización de dichas acciones se arraigará a la gente en sus comunidades y se generarán empleos rurales que ayuden a contener la migración. Además, no olvidemos que en el campo no solo se producen alimentos y existen recursos ambientales indispensables, sino que también se desarrolla una forma de vida sana, con valores morales y espirituales. Regresar al campo significa fortalecer una identidad cultural de la más alta calidad humana (López Obrador, 2016).

Mediante el posicionamiento de tales elementos cardinales el nuevo gobierno reconoció que la transformación profunda del país debe partir de la modificación de sus cimientos éticos, morales, axiológicos, culturales y espirituales y no solo de la implementación de acciones materiales o políticas pragmáticas conducidas por la urgencia coyuntural o el oportunismo del poder.

\section{EL MODELO DE COMUNICACIÓN DE LA CUARTA TRANFORMACIÓN HISTÓRICA DE MÉXICO}

Con el fin de alcanzar los objetivos planteados en el proyecto de la "Cuarta Transformación Histórica" el gobierno de AMLO/Morena expuso la necesidad de crear otro modelo de comunicación social que se convierta en un parteaguas que sepultara el tradicional prototipo de difusión de control político basado en el "arreglo económico" entre los concesionarios o propietarios de los medios y el tradicional Estado mexicano. Con ello, se establecería otro "pacto 
comunicativo" entre empresas de comunicación, sociedad y gobierno para acceder a una nueva relación más justa y equilibrada entre las partes $^{2}$. En este sentido, se pretendió introducir "una nueva reforma democrática, tan necesaria y trascendental, como fue el cambio político que se gestó en las elecciones federales de 2018 año, que tuviera la capacidad de corregir y superar los desaciertos y lagunas de la reforma estructural de telecomunicaciones, y modificar la relación que durante décadas se tejió entre el poder político y los medios de comunicación, así como las "reglas escritas" y las "reglas no escritas" que tanto daño hicieron a los derechos de libertad de expresión e información, a los derechos de las audiencias y a los consumidores" (Sosa Plata, 2018).

Dicho prototipo comunicativo permitirá informar de forma directa, constante y ágil a la población sobre las políticas públicas adoptadas por el novel gobierno para cumplir con el derecho a la información y crear una opinión pública favorable que le sirva de respaldo subjetivo para gobernar eficazmente. Tal política de comunicación se cimentará en una nueva racionalidad comunicativa sustentada en los siguientes veinte y seis ejes cardinales: la centralización de la comunicación, el ejercicio del derecho a la información, el respeto a la libertad de expresión, la democratización de la comunicación, no a la censura informativa, respeto al funcionamiento de los medios privados, revalorar el valor público de la información, austeridad comunicativa republicana, reducción del gasto publicitario gubernamental, combate a la corrupción informativa, fomento de la transparencia, apertura de los archivos del Centro de Seguridad $\mathrm{Na}$ cional (CISEN), de la Secretaría de Marina (SM) y de la Defensa Nacional (DN), evitar la discrecionalidad, implementación de las conferencias mañaneras, propiciar la "comunicación deliberativa”, aplicación de las consultas ciudadanas, incentivar la direccionalidad comunicativa, vinculación cotidiana directa con el pueblo, reordenamiento institucional de la infraestructura de la comunicación, impulso a los medios públicos y comunitarios, aprovechamiento de las nuevas tecnologías, Internet para todos, apoyo al periodismo independiente, retorno de voces críticas, protección a los comunicadores, entre otros (Jiménez, 2018).

Con el fin de comprender con mayor claridad las características que componen el nuevo modelo de comunicación de la "Cuarta Transformación Histórica", es necesario, por una parte, ubicar su estructura dentro de los principios básicos de la teoría de la comunicación. De esta forma, hay que tener presente que los postulados centrales de dicha teoría formulan que los procesos colectivos de comunicación social están conformados por cuatro elementos fundamentales que los determinan, y que abarcan al emisor (instituciones), al mensaje (discursos), al receptor (públicos o audiencias) y la dinámica de retroalimentación entre emisores y habitantes (respuestas ciudadanas o de los receptores).

Por otra parte, es fundamental distinguir entre los procesos de comunicación indirectos, que se dan vía las tecnologías masivas de difusión de información y las dinámicas de comunicación directa, que se establecen entre el emisor y los auditorios a través de plazas o espacios públicos, sin que intervengan las mediaciones tecnológicas.

En este sentido el nuevo prototipo de comunicación de la Cuarta Transformación está compuesto por dos grandes niveles de acción comunicativa que abarcan: por un lado, una fase indirecta de comunicación; y por otro lado, una fase directa de comunicación que en conjunto se convierten en la fuerza político-cultural que cotidianamente le imprimen la dirección colectiva de naturaleza cognitivo-psíquico-ideológicoemocional a la nación. De aquí, la necesidad de estudiar los procesos indirectos y directos que constituyen el nuevo proceso de comunicación de la sociedad mexicana.

\subsection{COMUNICACIÓN INDIRECTA VÍA LAS TECNOLOGÍAS DE INFORMACIÓN}

Retomando los planteamientos conceptuales anteriores los diversos elementos planteados por AMLO/Morena que conformarán su estrategia de comunicación indirecta como gobierno del cambio histórico para el período 2018-2024, y reordenándolos dentro de las cuatro fases anteriores del proceso básico de comunicación (emisor-mensaje-receptor-retroalimentación), observamos que éste prototipo comunicativo se caracterizó por estar constituido, entre otros, por las siguientes características esenciales:

\subsubsection{El emisor}

El proceso de emisión (instituciones), quedó constituido por los siguientes aspectos: la concentración de la comunicación, la igualdad ante los medios, la vinculación con los medios de comunicación privados, el reordenamiento de los medios públicos, impulso a los canales 
comunitarios, el apoyo al periodismo independiente, la protección a trabajadores de la comunicación, retorno a voces críticas, el uso de las nuevas tecnologías, etc.

\subsubsection{Los mensajes o contenidos}

La dinámica de producción de mensajes (discursos) abarcará los siguientes elementos: comunicación austera y republicana, reducción de la publicidad gubernamental, otorgamiento equilibrado de la publicidad oficial, centralización de los medios, democratización de la comunicación, no a la censura, no gobernar mediante el twetter, presencia de la conferencia mañanera, producción de contenidos de calidad, otorgamiento equilibrado de la publicidad gubernamental, límites a la propaganda oficial, etc.

\subsubsection{Las audiencias o públicos}

El proceso de recepción de la información (públicos o audiencias) por parte de la población estará conformado por los siguientes factores: la libertad de expresión, igualdad ante los medios, la opinión pública como apoyo a la gobernabilidad, el respeto a los derechos de las audiencias, etc.

\subsubsection{La bidireccionalidad o retroalimentación}

La acción de retroalimentación (respuestas ciudadanas) de los habitantes hacia el Estado, incluirá los siguientes elementos comunicativos: política de comunicación bidireccional, Internet para todos, realización de las consultas ciudadanas, comunicación horizontal, etc.

\subsection{COMUNICACIÓN DIRECTA CON LA POBLACIÓN}

La dinámica de comunicación directa comprende los procesos que se establecen entre el emisor y los auditorios a través de plazas públicas, kioscos, alamedas, explanadas, encuentros campesinos, presentaciones en auditorios, convocatorias indígenas, reuniones con productores rurales, etc. que distinguen al modelo de comunicación de AMLO/Morena, sin que intervengan las mediaciones tecnológicas; se caracteriza por estar constituido por los siguien- tes dos elementos: vinculación cotidiana con el pueblo y relación directa con los pobladores.

Con la definición de dichas pautas medulares ideológico-políticas y otras más expresadas por AMLO y los principales actores de Morena, se diseñó el nuevo modelo de comunicación de la Cuarta Transformación de la República que se establecerá entre el Estado, los medios de difusión y la sociedad para dirigir al país hacia un nuevo proyecto de desarrollo de 2018 al 2024.

\section{LOS DESAFÍOS DEMOCRÁTICOS DEL PROTOTIPO DE COMUNICACIÓN DE LA CUARTA TRANSFORMACIÓN}

Sin embargo, no obstante, la definición de los relevantes lineamientos constitutivos del nuevo proyecto de comunicación, es fundamental destacar que ante los grandes desafíos de desarrollo estructural que se deben resolver en México con el fin de edificar otra nación en el siglo XXI, es indispensable que la sociedad reconstruya los procesos democráticos de comunicación para el proceso de cambio de la nación se realice de manera equilibrada y no sesgada o viciada. Hay que subrayar que, en los comicios de 2018, la sociedad votó, en última instancia, por la amplia restauración de la democracia, el rescate de la seguridad ciudadana, el establecimiento de otra ética pública, el combate a la corrupción, la impunidad, la justicia y el desarroIlo virtuoso de la República; y no por el simple empoderamiento de otro grupo político en el poder que repita los mismos excesos autoritarios y escandalosos que criticó de sus antecesores.

Por ello, para refundar la democracia y orientar a la nación en otra dirección no sólo se requiere atraer nuevas inversiones externas, crear más infraestructura, invertir en los polos marginados, separar el poder político del poder económico, ejecutar nuevos procesos electorales pulcros, formar otro sistema de seguridad, descentralizar la administración pública, reorientar el proyecto educativo, etc.; sino también es fundamental que los ciudadanos y el gobierno edifiquen otro pacto de relación comunicativa directa entre el Estado y las comunidades, ya que la cimentación de la democracia necesariamente cruza por la apertura, la diversidad y el debate respetuoso de concepciones e ideas que permitan edificar una opinión pública enriquecida que contribuya a polemizar y rencausar las decisiones del Estado. Un régimen democrático exige la existencia y el respeto de múltiples 
corrientes de pensamiento que nutran sólidamente el espacio de la opinión pública para que los ciudadanos se informen plural y oportunamente sobre los diversos hechos de la realidad, y en base a ello, tomen las mejores decisiones para sus vidas.

Dentro de la refundación de este nuevo pacto político-social los medios de comunicación colectivos deben mantener una sana distancia del poder político y económico, pues:

el peor error que podrían cometer los medios y el presidente electo es volcarse a alimentar una opinión aduladora, zalamera y proclive que socave la crítica autónoma. Nada más saludable y ejemplar para la democracia y el nuevo régimen que mantener relaciones independientes con los medios que incluyan el diálogo constante y respetuoso con la disidencia. (Benassini Félix, 2018).

En este sentido, para edificar el nuevo proyecto de nación de la Cuarta Transformación histórica, el Estado debe salvaguardar la posición analítica y crítica argumentada de los periodistas y comentaristas ante la política y otras acciones gubernamentales, pues su función esencial es operar como contrapesos vigilantes del poder establecido, para contribuir a reconstruir el tejido democrático y las bases civilizatorias elementales que permitan impulsar equilibradamente el crecimiento nacional y la consolidación de la paz social.

En consecuencia, ante la conquista del formidable poder alcanzado por AMLO/Morena para gobernar a la nación durante el periodo 20182024, será fundamental que además del funcionamiento de las redes sociales independientes, el gobierno permita que la propia sociedad y no tanto el Estado, cree un vigoroso modelo de comunicación ciudadano autónomo, plural, abierto e interactivo con mecanismos medibles de independencia, transparencia y rendición de cuentas, que admita que los habitantes expresen libremente su sentir sobre si el reciente sistema de gobernabilidad de izquierda inaugurado en México cumple o no con las expectativas prometidas a los ciudadanos, o debe corregir el diseño de sus políticas públicas y su implementación correspondiente. Dicho modelo no debe ser centralizado, ni controlado por la nueva cúpula de poder, sino coordinado por la sociedad para mantenerlo abierto a la expresión del mayor flujo de opiniones ciudadanas con el fin de fomentar la interacción de la pluralidad y la diversidad de puntos de vista en el espacio público, evitando el autoritarismo, la censura, el abono al "culto a la personalidad", y el restablecimiento de un nuevo "pensamiento único" en
México, que ya no sea la doctrina del "neoliberalismo modernizador", sino ahora se substituya por la ideología de la izquierda burocrática o dogmática.

En este sentido, la moderna relación entre gobierno, medios y ciudadanos de la "Cuarta Transformación” del nuevo régimen lopezobradorista, debe modificar el antiguo vínculo existente entre dichos tres sectores, para evitar que dicho cambio histórico termine siendo un neo caudillismo reciclado del PRI o una reproducción maquillada del PAN (Albarrán de Alva, 2018), o se convierta en una nueva "elite política dorada" que abuse de la sociedad (Albarrán de Alva, 2018). Debido a esto, la publicidad oficial debe dejar de ser un instrumento para premiar las líneas editoriales de los medios afines al relato oficial en turno y castigar a los canales críticos y contestatarios (Calleja, 2018); sino que debe convertirse en una herramienta eficaz para fomentar la libertad, el análisis complejo de la realidad, la independencia informativa y la ciudadanización de la comunicación, con objeto de erigir una opinión pública fuerte que actúe como cimiento para la construcción del nuevo país que se anhela, y en algunos momentos, como contrapeso al poder vigente.

Hay que recordar que la experiencia histórica demuestra que la concentración del poder absoluto, corrompe absolutamente y la centralización unilateral de la información termina creando "absolutismo cognitivo", que es veneno para la democracia.

De lo contrario, si el nuevo modelo de comunicación de la Cuarta Transformación de la República no abre caminos para la participación de todos los ciudadanos en el espacio público, especialmente mediático, y solo se convierte en la reconstrucción de la nueva "Aguja Hipodérmica" para inculcar a través de su prototipo de difusión masivo la propaganda morenista a la sociedad; se volverá a concentrar gradualmente, a mediano plazo, una fuerte desilusión, malestar, irritabilidad y desencanto colectivo que despertará con mayor fuerza al tigre del "México Profundo" que momentáneamente se apaciguó con la promesa de alcanzar una nueva esperanza civilizatoria para todos los habitantes de la nación. El "México Profundo" es sabio y siempre sabe cuándo se le engaña, y en consecuencia reacciona con furia hasta alcanzar justicia.

En síntesis, en este proceso de profundo cambio histórico de la segunda década del nuevo siglo, las universidades, especialmente públicas, ocupan un rol estratégico muy importante para reposicionar el trabajo de investiga- 
ción y reflexión académica, fuera de las pasiones o fervores ideológicos partidistas, para examinar lo más objetivamente los avances que se han logrado con la realización del nuevo Proyecto de Nación en México y los retrocesos respectivos que también se han generado paralelamente con la aplicación de dicha iniciativa histórica. Dentro de este escenario, las escuelas de comunicación del país tienen una responsabilidad e importancia central para analizar si lo que se realiza a través de la ejecución del nuevo paradigma de comunicación de la Cuarta Transformación es para crear democracia, pluralidad y libertad de expresión o es para construir centralismo, autoritarismo y Presidencia Imperial.

\section{NOTAS}

\footnotetext{
${ }^{1}$ AMLO es el candidato con más votos en la historia de México (2 de julio de 2018). Forbes. Recuperado de: https://www.forbes.com.mx/amlo-es-el-candidato-con-masvotos-en-la-historia-de-mexico/; Elecciones México 2018: Ios ganadores y perdedores de la jornada (2 de julio de 2018). CNN Español. Recuperado de:

https://cnnespanol.cnn.com/2018/07/02/eleccionesmexico-2018-los-ganadores-y-perdedores-de-la-jornada/; Morales, C. (3 de julio de 2018). López Obrador dominó hasta con $79 \%$ de los votos en los estados. Forbes. Recuperado de: https://www.forbes.com.mx/lopez-obradordomino-hasta-con-79-de-los-votos-en-los-estados/; García, C. (5 de julio de 2018). Tuvo AMLO 30 millones 47 mil votos, según cómputos distritales. El Universal. Recuperado de: http://www.eluniversal.com.mx/elecciones-2018/computosdistritales-del-ine-dan-53-de-la-votacion-amlo; ¿Qué puede hacer AMLO con su mayoría en Congreso? ( 5 de julio de 2018). ADNPolítico. Recuperado de:

https://adnpolitico.com/congreso/2018/07/05/que-puedehacer-amlo-con-su-mayoria-en-congreso; Elecciones en México: el único estado de los 32 de México en el que no ganó López Obrador (5 de julio de 2018). BBC News Mundo. Recuperado de: https://www.bbc.com/mundo/noticiasamerica-latina-44689634; Navarro, M. F. (6 de julio de 2018). Cómputo final: AMLO se lleva 30.11 millones de votos, 53.19\%. Forbes. Recuperado de:

https://www.forbes.com.mx/computo-final-amlo-se-lleva-3011-millones-de-votos-53-19/; Urrutia, A. (9 de julio de 2018). Valida el INE triunfo de Juntos Haremos Historia. La Jornada, p. 4.

2 Urdiales, C. (26 de agosto de 2018). La comunicación social de AMLO. La Razón. Recuperado de:

https://www.razon.com.mx/columnas/la-comunicacionsocial-de-amlo/; Coronel, M. y Padilla, C. (2018). Fin a una era, nunca más. No pago para que me peguen: Jesús Ramírez Cuevas. Zócalo, 225, p. 37.
}

\section{REFERENCIAS BIBLIOGRÁFICAS}

- Albarrán de Alva, G. (2018). Hacia un nuevo modelo de relación prensa-gobierno. Zócalo, (224), 9.
- AMLO y doce de sus políticas (21 de noviembre de 2016). Revista Proceso.Com. Recuperado de: https://www.proceso.com.mx/463327/amlodoce-sus-polemicas-propuestas-2018.

- Benassini Félix, C. (2018). López Obrador y la importancia del pluralismo mediático. Zócalo, (224), 14.

- Calleja, A. (24 de julio de 2018). Publicidad oficial y ¿la nueva? relación con los medios. La Silla Rota. Recuperado de:

https://lasillarota.com/opinion/columnas/publici dad-oficial-y-la-nueva-relacion-con-losmedios/236883.

- Jiménez, G. (10 de septiembre de 2018). Vocero de AMLO anuncia reformas en materia de medios. EI Sol de Puebla. Recuperado de:

https://www.elsoldepuebla.com.mx/mexico/politi $\mathrm{ca} /$ vocero-de-amlo-anuncia-reformas-en-materiade-medios-1983092.html.

- López Obrador, A. M. (20 de noviembre de 2016). Lineamientos Básicos del Proyecto Alternativo de Nación 2018-2024. En II Congreso Nacional Extraordinario de Morena. Congreso llevado a cabo en Ciudad de México, México. Recuperado de: https://lopezobrador.org.mx/2016/11/20/lineam ientos-basicos-del-proyecto-alternativo-de-nacion2018-2024-anuncia-amlo/.

- López Obrador, A. M. (1 de diciembre de 2018). Discurso Andrés Manuel López Obrador al rendir protesta como presidente. Animal Político. Recuperado de:

https://www.animalpolitico.com/2018/12/discur so-integro-amlo-protesta-presidente/.

- López Obrador, A. M. (22 de enero de 2019). Conferencia de prensa del presidente para informar sobre la crisis de valores en México. Comunicación Social, Presidencia de la República, Ciudad de México. Recuperado de: https://www.gob.mx/presidencia/prensa/preside nte-andres-manuel-lopez-obrador.

- López Veneroni, F. (2019). Puntos para el análisis del discurso de Andrés Manuel López Obrador como Presidente Constitucional. Revista Zócalo (227), 29-31.

- Morena (2018).Programa del Movimiento Regeneración Nacional. ¿Por qué luchamos? Lopezobrador.org. Recuperado de: https://lopezobrador.org.mx/programa-delmovimiento-regenarcion-nacional/.

- Morena (2018b). Proyecto de Nación 2018-2024. La esperanza del cambio. Recuperado de: https://drive.google.com/file/d/11B0aNBuVpHB7 GDVXhCKdYvVKw7D7Ta-x/view.

- Mussali, R. (10 de julio de 2018). El verano mexicano en el contexto político latinoamericano. ADN Político. Recuperado de: 
https://adnpolitico.com/voces/2018/07/10/opini on-el-verano-mexicano-en-el-contexto-politicolatinoamericano.

- Salinas, P. (2 de julio de 2018) Elección México 2018: Una lección para la historia. ADN Político. Recuperado de:

https://adnpolitico.com/voces/2018/07/02/opini on-eleccion-mexico-2018-una-leccion-para-lahistoria?internal_source $=$ PLAYLIST .

- Sosa Plata, G. (9 de octubre de 2018). La Cuarta Transformación de los medios. SinEmbargo.com. Recuperado de: https://www.sinembargo.mx/0910-2018/3481867?fbclid=IwAR0U0wogyAg7ch75aIg_ARK97y3MTc5DZpJjuQ6NZoBzAViICVQXwD OPRs. 